\title{
LANGUAGE DEVELOPMENT OF THE CLEFT PALATE CHILD
}

\author{
LORETTA HORN, B.A. (SP. \& H. THERAPY) (RAND) \\ Speech Therapy Department, General Hospital, Johannesburg
}

\section{SUMMARY}

The ITPA was used in an assessment of the psycholinguistic abilities of three cleft palate children and three matched normal children, of ages ranging from 48 months to 66 months. The data obtained revealed that the cleft palate children manifested a general depression in those areas sampled by the ITPA, in particular in areas testing expressive abilities.

A transformational analysis of the language samples of the cleft palate children showed the relative immaturity of the syntactic structures used by these children.

In spite of the limitations of this study, there was a clear indication of a language retardation in the cleft palate group. Several factors present in the early development of cleft palate children could adversely affect the acquisition of language skills. The implications of these findings for speech therapy are important.

\section{OPSOMMING}

Drie kinders met gesplete verhemeltes is vergelyk met drie normale kinders ten opsigte van psigolinguistiese vermoëns deur middeI van die ITPA. Die ouderdomme van die kinders het gewissel van 48 maande tot 66 maande. Die toetsresultate het aangetoon dat die kinders met gesplete verhemeltes oor die algemeen swakker gevaar het in die toetsgebiede van die ITPA, in besonder in die items wat uitdrukkingsvermoë toets.

Die analiese van die taalvóorbeelde van die kinders met gesplete verhemeltes was gebasseer op 'n generatief-grammatiese benadering. Hierdie analiese het getoon dat die sintaktiese strukture soos gebruik deur hierdie kinders relatief onont wikkeld was.

Nieteenstaande die tekortkominge van hierdie ondersoek is daar tog 'n duidelike aanduiding van vertraging in die taalstruktuur van die kinders met gesplete verhemeltes. Die aanleer van linguistiese vaardigheid word in die vroeë ontwikkeling van hierdie kinders deur verskeie faktore beînvloed. Die bevindings in hierdie verband is belangrik vir spraakterapie.

Literature on the subject of cleft palate and communication problems has been concerned primarily with the adequacy of articulation, and a great deal of information is available on the speech characteristics of individuals with clefts. Most investigators have dealt with the speech output in terms of the defective elements which make it acoustically different from normal speech. Discussions of cleft palate communication problems usually exclude information about language skills. Only recently has attention been directed 
beyond the mechanics of the speech production of the cleft palate child to the fundamental language structures which are basic to communication.

Many problems associated with the occurrence of cleft palate, such as parental reactions to the defect, modified feeding methods, hearing loss, overprotection and lack of rewards for early speech attempts, and the unintelligibility of early speech, may have adverse effects on the development of language. Clinical observation and parental reports have frequently indicated an apparent retardation in language acquisition, and some texts ${ }^{6,21}$ make reference to the retardation of communication skills of cleft palate children. There has, however, been a paucity of systematic research into the language development of cleft palate individuals. Relatively few studies have been carried out to experimentally investigate the language of children with clefts. It was felt, therefore, that consideration of this subject would yield useful information on the cleft palate problem and the factors influencing language acquisition.

Some investigators have attempted to study the language abilities of cleft palate children. Bzoch ${ }^{3}$ reported a considerable delay in early speech developmental patterns in over $50 \%$ of his cleft palate subjects. Further studies, directed more specifically towards language development, have yielded conflicting results. Spriestersbach, Darley and Morris ${ }^{20}$ used measures of language such as mean length of response, structural complexity score and vocabulary size, and found that cleft palate children were retarded on measures of verbal output and vocabulary usage, but that they demonstrated no general language retardation. In a study using more extensive measures of language Morris ${ }^{16}$ found that the cleft palate children were significantly retarded ". . on every measure of communication skill for which comparisons with normal children were possible". Smith and McWilliams ${ }^{19}$ used the Illinois Test of Psycholinguistic Abilities to assess the language skills of 136 cleft palate children of three to eight years of age. They reported a depression in all nine areas of language evaluated. Philips and Harrison ${ }^{17}$ evaluated the language abilities of 137 cleft palate children and compared these with 165 noncleft children. They made use of the Peabody Picture Vocabulary Test, Mecham's Verbal Language Development Scale, together with items selected from the Kuhlman Binet, the Stanford-Binet, the Cattell, and the Baker's Detroit Test of Learning Aptitude, as measures of language comprehension and expression. The children tested were between the ages of 18 and 72 months. The cleft palate subjects were found to be retarded in both receptive and expressive language abilities. The older cleft palate children ( 6 year level) were found to have a relatively greater degree of retardation in language skills, which implied that the language delay had not been overcome with maturation. They stressed the need for language stimulation programs for pre-school cleft palate children.

From the studies mentioned above, it appears that children with cleft palates are often retarded to some degree in language development. Decreased verbal output and more simple language structures have been reported. These findings support the hypothesis that the consequences of cleft lip and palate are much more than those of an anatomical defect alone. 
Studies of this type have been based on quantitative measures of language which, although they did indicate gross developmental changes, did not yield information about the language structure as a whole. Rather, they stressed different, isolated aspects of utterances without giving attention to the linguistic system which underlies the verbal activity of the speaker. It is this abstract system of rules enabling the individual to generate the sentences in his language, that linguists seek to describe. Advances in linguistics, in particular the transformational model of grammar developed by Chomsky 5 , have made possible more accurate and meaningful descriptions of language structure, and this has resulted in increased interest in the study of child language. The development of transformational generative grammar has had considerable influence on current research in language development.

Due to the limitations of the previously used language measures the present study included an analysis of language based on the transformational generative model, thereby taking into consideration the system of rules assigning structural description to utterances.

In the present study the writer was concerned primarily with the children's acquisition of syntax, i.e. methods of combining words into sentences. In a surprisingly short period of time children acquire almost full knowledge of the grammatical system of their native language. It is postulated that in acquiring language the child incorporates a system of rules which formulates underlying regularities enabling him to generate utterances. The grammar of the linguist aims to describe the linguistic knowledge internalized by fluent speakers of a language; i.e. their linguistic "competence".

The syntactic component of the grammar has different levels:

Phrase-structure level. At this level underlying strings which implicitly define the basic grammatical relations in the sentence are formulated by means of rules specifying the arrangement of lexical items.

Transformational level. More complex sentences are derived from base structure strings by the application of transformational rules, which involve operations of addition, deletion, substitution and re-arrangement of constituents. The distinction between deep structure and surface structure is central to the theory of transformational grammar. The deep structure of a sentence, which is the representation of the meaning of the sentence, is transformed by syntactic rules into a structure which is ultimately spoken or written, called the surface structure.

Morphological level. At this level inflectional rules, dependent on the previous application of sequential rules, are applied.

In addition to the linguistic analysis of syntactic structures, a further measure of language skill was employed in the present study. In an attempt to compare the various psycholinguistic abilities of cleft palate and normal children, the Illinois Test of Psycholinguistic Abilities (ITPA) was used. Although this language test has been found to have limitations ${ }^{12}$ it appears to be a comprehensive test of children's language status. 
Factors influencing the language development of the cleft palate child.

It is important to realize that the learning processes underlying the development of language are themselves dependent upon the existence and maintenance of certain conditions in the organism and environment. The psychosocial environment of the infant and young child during the years of language acquisition has to be taken into account when.considering the development of language.

Several psychosocial factors operating in the cleft palate population may have major impact on the total development of communication skills. From the very beginning the life experiences of the baby with a cleft are different to those of noncleft infants. Appearance, feeding, dentition, surgery and general care often cause much concern. Parental reactions of disappointment, guilt, defensiveness and resentment are frequently encountered. Spriestersbach and Sherman ${ }^{21}$ pointed out:

... in few other clinical diagnoses is there as much likelihood of finding parental feelings of guilt, rejection and overcompensation, any of which would influence the interpersonal relationships between parent and child and in turn affect communication skills of the child.

The reactions of parents to the birth of a cleft palate child have been investigated and reported. ${ }^{22}$ We must stress the importance of looking beyond the anatomical defect to the child himself and his parents.

The role played by reinforcement in early language development has often been noted. The vocalizations of the cleft palate baby may not be rewarded to the same extent as those of the normal infant due to the lack of a warm, pleasurable relationship with the mother. Artificial feeding methods, and the possible deprivation of normal oral experiences, together with a failure to satisfy the basic sucking and hunger drives of the infant can adversely affect the development of speech and language.

A well recognized aspect of the cleft palate problem is the effect on speech intelligibility. It is felt that parental reactions to the early defective speech patterns may cause or aggravate the problems in language development. The utterances of the child with a cleft palate are often so different to those of the normal child, due to structural inadequacies, that they may be greeted with much less enthusiasm by parents. Parents' failure to recognize early . utterances or even outright rejection of such vocalizations could result in deprivation of normal feedback and reinforcement. Speech models and language stimulation through "imitation with expansion" by parénts are felt to play an important role in language learning. Brown and Bellugi ${ }^{2}$ Spriestersbach and Sherman ${ }^{21}$ pointed out that in his failure to improve his approximations of the speech models he hears the cleft palate child may tend to withdraw from the activity and make fewer attempts to perfect his linguistic skills. Parents may fail to expand the immature utterances of the cleft palate child because they do not expect better attempts from the child, or because the unintelligibility of utterances makes such repetition and expansion impossible. 
It is common to find that cleft palate children have varying degrees of hearing loss. Conductive losses often occur intermittently, especially at an early age. The possibility of a hearing loss during the important years of language acquisition has to be taken intoaccount in the study of cleft palate children's language development.

It is clear that there are several factors which could adversely influence the development of language in the child with a cleft palate.

\section{METHOD}

The aim of the present study was to investigate the language skills of a group of cleft palate children. An experimental group of children with clefts, and a matched control group without clefts were compared with regard to their performance in the psycholinguistic areas tested by the ITPA, and the complexity of syntactic structures ušed.

\section{Subjects.}

The experimental group consisted of 3 children with complete clefts of the lip and palate ( 2 unilateral and one bilateral), of ages 48 months, 54 months and 66 months. These children were all being treated at the Speech and Hearing Clinic, University of the Witwatersrand. The control group consisted of 3 normal children aged 47 months, 51 months and 63 months. The children in the two groups were all boys, of matched socio-economic status. All had intelligence quotients in the normal to bright-normal range, and none had hearing losses of "educational significance" 7

\section{Materials.}

The Illinois Test of Psycholinguistic Abilities was administered to each subject. Certain modifications of the test were introduced as suggested by Phillips ${ }^{18}$, who reported on the use of this test with English children.

The stimulus materials used to obtain samples of language from the children consisted of two books with brightly-coloured pictures depicting everyday activities, toy motorcars, and a set of pictures chosen by the investigator to elicit certain responses.

Sentences consisting of vocabulary items present in the speech of young children, but containing syntactic structures more complex than those present in the sample of the child's spontaneous speech were constructed for each child. For example, a child who gave no evidence of applying a passive transformation in the language sample obtained was presented with sentences containing this construction. The child was first required to repeat the sentence after the investigator, and thereafter he was asked to point to the appropriate picture, demonstrating his understanding of the sentence.

Such sentence imitation and comprehension tasks have been suggested as means of assessing the linguistic competence of children. 9,15 : The distinction between competence and performance makes adequate assessment of 
children's linguistic levels difficult. The description which is of the greatest relevance is clearly the measure of competence, not that of performance. The majority of research studies have been based on linguistic descriptions of utterances produced, and to a lesser extent utterances understood by children at various stages of development. The present study is limited in that it is based, to a large extent, on performance. The repetition and comprehension tasks were applied to only some transformations, in an attempt to measure the competence of the child in these areas.

\section{Procedure.}

The subjects were tested individually in familiar surroundings. The ITPA was administered to each child, after hearing and intelligence had been tested. On another occasion the spontaneous speech of the child in response to the stimulus materials and the investigator's conversation was tape-recorded. The children were later presented with the repetition and comprehension tasks, which were based on the samples previously obtained. The speech sample of each child consisted of about 60 to 80 ut terances. All utterances were taperecorded and later written out in traditional orthography. The language samples were then analyzed according to the transformational rules and restricted structures tabulated by Menyuk ${ }^{13}, 14$. The syntactic structures of the cleft palate children were compared with those of the normal children of matched ages.

Analysis of syntactic structures. The analysis of structures in this study was based on the model proposed by Menyuk as a technique for describing children's grammar. The model is based on a generative grammar approach to linguistic structure.

In the studies of Menyuk ${ }^{13,14}$ and Brannon ${ }^{1}$ it was found that differences in levels of language development could be detected in terms of the transformational rules acquired, and the restricted structures present at successive age levels. There is similarity in the sequence of acquisition of structures through the developmental period. It was, therefore, felt that an analysis according to the rules exemplified in Menyuk's descriptive model would yield information about the level of language development of the two groups tested. The samples were compared in terms of the use of the phrase structures, transformations and morphophonemic entities listed by Menyuk ${ }^{13}, 14$.

Menyuk's table of syntactic structures includes 14 simple transformations such as passive, negation, question and imperative, together with 12 generalized transformations such as conjunction, relative clause, complement and adjective. The list also includes various structures which are restricted to a children's grammar. On the phrase structure level these involve restrictions in the formation of the verb phrase, noun phrase, prepositions, articles and particles. Transformational restrictions include contraction deletion, no question, pronoun restriction, etc., and morphological deviations in the verb form, noun form, possessive and pronoun are listed. 


\section{RESULTS}

From the norms of the ITPA the language age and standard scores for each subject were computed. The two youngest cleft palate children had language ages which were below their chronological ages. The language ages of the cleft palate group were all below those of the normal group.

In order to compare the performance of the subjects on the various subtests the ranges were calculated for each subtest, as recommended in the ITPA Manual, McCarthy and Kirk ${ }^{11}$. Two of the cleft palate subjects demonstrated a significant deficiency in the vocal encoding and motor encoding subtests, while the eldest cleft palate subject showed no significant weakness in these areas. The control subjects all showed relatively normal and stable patterns of performance in all areas, with no significant differences between the subtest performances.

To enable comparison between the performances of the two groups a composite profile was plotted using the means of the standard scores for each different subtest. (Figure 1.)

The results of this study indicated that the cleft palate children performed significantly poorer than the normal children on the following subtests: Vocal Encoding, Motor Encoding, Auditory-Vocal Automatic and VisualMotor Sequential. Figure 1. indicates that the cleft palate subjects tended to show a general depression in the psycholinguistic areas tested by the ITPA.

\section{Analysis of syntactic structures.}

The description and classification of the linguistic data using Menyuk's table of transformations and immature structures yielded valuable information about the syntactic structures present in the language samples of the two groups. Clear differences were revealed between the language structures of the cleft palate children and the normal children.

The most marked difference between the two groups was the large proportion of structures restricted to children's grammar appearing in the language samples of the cleft palate group. These were much less common in the samples of the control group. At the two youngest age levels tested such unique forms constituted over $50 \%$ of the utterances, whereas restricted forms accounted for a much smaller percentage of the normal children's utterances. At the phrase structure level there was frequent omission of noun phrases, articles and prepositions. The utterances were clearly indicative of rules applied in the early stages of language acquisition. The tendency toward the lack of expansion of a syntactic class on the phrase structure level, 

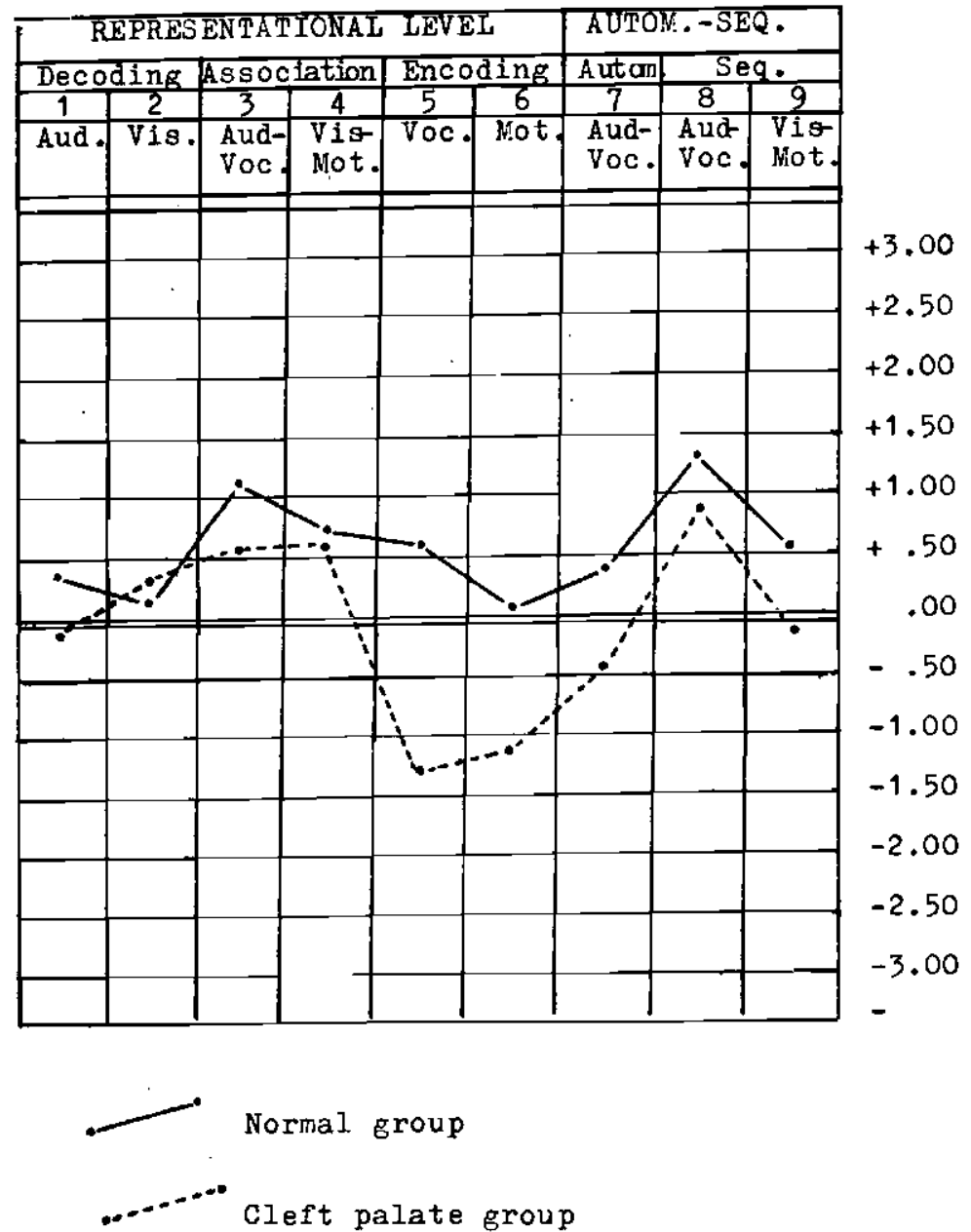

Figure 1. Profiles of the two groups (cleft palate and noncleft palate) on the ITPA.

resulting in an immature syntactic structure, was much more marked in the cleft palate group than in the normal group. There was clear evidence of late development of the auxiliary and model verbs, and the omission of the contracted form of the auxiliary "be" (contraction deletion) was often present in the samples of the experimental group. The language structures of the control group were more frequently well-formed, including correct expansion of the auxiliary node. At the morphological level there were omissions, substitutions and redundancies particularly of the verb form. In the use of generalized transformations the normal children at the younger age levels were again superior. While the normal children frequently expanded sentences through the use of conjunctions, the cleft palate children showed 
very limited ability in the use of conjunctions. Restricted structures, involving omission of syntactic classes, violation of selectional restrictions and incorrect application of transformational operations were more numerous than correct transformational structures in the utterances produced spontaneously and in repetition by the younger cleft palate children.

A marked difference, for example, between the control and experimental group was noted in the structure of interrogative utterances. Wh-questions used by the cleft palate children were predominantly formed by the simple addition of an interrogative word to the declarative sentence structure, e.g. "where it is?" Yes/no questions were formed by means of the application of intonational markers, without the inclusion of the auxiliary verb. These types of structures were clearly indicative of an early stage in the acquisition of transformational structures. The normal group revealed a greater linguistic competence through the earlier use and inversion of the auxiliary verb for generating correct question transformations.

At the five-year age level the differences in the syntactic structures used by the two children were less marked. Both had acquired basic syntactic structures, and there was no-significant difference between the base structures used by the normal child and the cleft palate child. On the transformational level the normal child used the correct form of the auxiliary verb more consistently, and gave evidence of greater syntactic competence in the application of generalized transformations.

At each of the age levels considered in this study, but especially at the two younger age levels, the normal children gave evidence of more advanced linguistic competence through the decreased occurrence of restricted forms, and the greater proportion of grammatically correct transformations present in their language samples.

\section{DISCUSSION}

The cleft palate subjects in this study tended to show a general depression in those areas sampled by the ITPA. The normal children were generally superior in the nine psycholinguistic areas investigated. Figure 1, demonstrates the similarity in the shape of the profiles of the two groups, but clearly the difficulties of the normal subjects were not as marked as those of the children with clefts. The ITPA revealed that the cleft palate children had a significant disability in the area of encoding, relative to their own performance in other psycholinguistic areas and in comparison with the performance of the normal children. The marked difficulty demonstrated in the vocal expression of ideas could be due to factors present in the early developmental period of the cleft palate children. Less satisfying mother-child interaction, fewer speech models and decreased reinforcement of deviant speech patterns may have an adverse effect on the development of language skills. The possible effects of temporary hearing losses in the earlier stages of language development in the se children 
must not be overlooked. The deficiency in the motor expression of ideas (i.e. gesture) can be associated with the general shyness, inhibition and dependency observed in the cleft palate group. These children are often overprotected by parents, and although parents might not view the child as "defective" they of ten feel he is "special" or "different" in some way, and therefore react to him in unrealistic ways. These children have often been found to be deperident on their parents, shy, and lacking in general spontaneity and initiative.

Another interesting finding was the significant difference between the performance of the two groups on the Auditory-Vocal Automatic subtest. This is a form of grammar test requiring the use of increasingly less familiar English inflections, in a sentence completion task. To learn such grammatical rules the child requires adequate speech models, and it is postulated that a poor mother-child relationship, together with the unintelligibility of the child's early utterances could make the process of imitation with expansion less spontaneous, and the provision of speech models less frequent. These factors may also reduce the chances of reinforcement contingent on the child's vocal responses. These, and numerous other factors present in the early developmental period of the child with a cleft, together with the possibility of temporary hearing loss at some stage, could account for the deficiency found in this aspect of linguistic performance.

The inferiority of the cleft palate children on the Visual-Motor Sequential subtest has also been reported by Smith and McWilliams ${ }^{19}$. They reported the consistent weakness of the cleft palate children in visual memory as an "interesting, although somewhat perplexing, finding". These writers considered the possibility of a general visual-motor deficit in cleft palate children. It appears that this area requires more extensive investigation.

The results of this study are limited by the small number of children tested. It must be stressed that the results reported are not taken as being conclusive, but are merely an indication of the areas of difficulty found in the cleft palate population.

Developmental trends in the acquisition of syntactic structures have been described in studies by Menyuk ${ }^{13,14}$ and Brannon ${ }^{1}$. The increased use of various transformational structures and decrease in the occurrence of deviant forms in the generation of structures during the normal process of language acquisition have been described. Although a limited sample of language was obtained, and only selected syntactic structures were considered in this study, there was clear evidence of greater syntactic maturity in the language of the normal group as compared with the matched cleft palate group.

The immature structures used by the two youngest cleft palate children were characteristic of the syntactic forms found in the utterances of much younger children. The occurrence of restricted structures, the late development of the auxiliary node, the lack of selectional restrictions and the limited use of transformational operations indicated that the cleft palate children were delayed in their acquisition of syntactic structures as compared with the control group. The writer feels that this immaturity of syntax could be 
accounted for in terms of the unique problems associated with the occurrence of cleft palate. The possibility of undetermined degrees of hearing loss at earlier stages in the development of these children must be kept in mind. Once again the failure of the cleft palate children to modify and transform the early patterns into more complex grammatical structures at the same age level as the normal children could be due to parents' failure to recognize or accept the early distorted speech attempts, resulting in deprivation of normal feedback and reinforcement. Many of the factors present in the early developmental period of the cleft palate child could have an impeding effect on the acquisition of language skills.

The results of this investigation give an indication of the problems involved in the development of communication skills in the cleft palate population. The findings reported here have significant implications for diagnostic and therapeutic procedures with cleft palate children. The assessment of children with clefts should include a thorough evaluation of language skills in addition to the traditional speech analysis. The therapist must be aware of the possibility of delay in language acquisition when counselling and interviewing parents of children with clefts. Speech therapists are often concerned only with the adequacy of the speech production, and give no attention to the language abilities of the cleft palate child.

In the consideration of treatment, the concept should be changed from speech correction to the facilitation of language development together with improvement of speech production. What the parents often need is information, together with counselling and emotional support. They need information about the cleft palate syndrome, as ignorance about such matters as etiology, feeding problems, surgery and speech therapy often leads to increased tension in the parent-child relationship.

These parents also need information concerning language development. Activities such as the provision of good speech models, continuous stimulation and motivation, the imitation of the child's utterances with expansion, and constant reinforcement of speech attempts come spontaneously within the normal parent-child relationship; in the interaction between the cleft palate child and his mother the spontaneous occurrence of these activities cannot always be assumed. The speech therapist must be prepared to train and advise mothers, and approach treatment with a knowledge and awareness of language acquisition processes. The habilitation program for the preschool child should include facilitation of language growth and development, and the positive aspects of inter-personal relationships through language should be emphasized.

\section{CONCLUSION}

The descriptive method used in this study for investigating syntactic structures indicated a developmental immaturity in the language of the cleft palate group. The data obtained from the ITPA results also indicated a general language depression in this group, with particular weaknesses in vocal 
expression, gestural output, auditory-vocal automatic abilities and visual memory in comparison with the normal children tested.

It appears that there is some degree of language retardation in cleft palate individuals; but the factors responsible for this delay cannot be isolated. The generalization of these findings to pre-school cleft palate children on the whole can be made only tentatively, due to the limited number of children tested in this study. Clearly, not all children with clefts exhibit a retardation in language skills.

\section{REFERENCES}

1. Brannon, J.B. (1968): A comparison of the syntactic structures in the speech of 3- and 4-year old children. Language and Speech, 11(3), 171-181.

2. Brown, R. and Bellugi, U. (1964): Three processes in the child's acquisition of syntax. In E.H. Lenneberg (Ed.), New Directions in the Study of Language, M.I.T. Press.

3. Bzoch, K.R. (1959): A study of the speech of a group of preschool cleft palate children. Cleft Palate Bulletin, 9(1), 2-3.

4. Chomsky, N. (1964): Formal discussion. Monographs of the Society for Research in Child Development, 29(1), 35-39.

5. Chomsky, N. (1965): Aspects of the Theory of Syntax. Cambridge, Mass., M.I.T. Press.

6. Grabb, W.C. and Rosenstein, S.W. and Bzoch, K.R. (Eds.). (1971): Cleft Lip and Palate: Surgical, Dental and Speech Aspects. Little, Brown and Company, Boston.

7. Hayes, C.S. (1965): Audiological problems associated with cleft palate. Proceedings of the Conference: Communicative problems in cleft palate. ASHA Reports No.1, 83-90.

8. Jacobs, R.A. and Rosenbaum, P.S. (1967): Grammar 2. Ginn and Company, Boston.

9. Lackner, J.R. (1968): A developmental study of language behaviour in retarded children. Neuropsychologia, 6, 301-320.

10. Lee, L. (1966): Developmental sentence types: a method for comparing normal and deviant syntactic development in children's language. $J$. Speech and Hearing Dis., 31, 311-330.

11. McCarthy, J.J. and Kirk, S.A. (1961): Illinois Test of Psycholinguistic Abilities: Examiner's Manual, Institute for Research on Exceptional Children. Univ. of Illinois, Urbana, Illinois.

12. McCarthy, J.J. and Olson, J.L. (1964): Validity Studies on the Illinois Test of Psycholinguistic Abilities. Institute for Research on Exceptional Children. Univ. of Illinois, Urbana, Illinois.

13. Menyuk, P. (1963): Syntactic structures in the language of children. J. Child Development, 34, 407-422.

14. Menyuk, P. (1964): Syntactic rules used by children from pre-school through first grade. Child Development, 35, 533-546.

15. Menyuk, P. (1969): Sentences Children Use. M.I.T. Press. 
16. Morris, H.L. (1962): Communication skills of children with cleft lips and palates. J. Speech and Hearing Dis., 5, 79-90.

17. Phillips, B.J. and Harrison, R.J. (1969): Language skills of preschool cleft palate children. Cleft Palate Journal, 6, 108-119.

18. Phillips, C.J. (1968): The ITPA: A report on its use with English children, and a comment on the psychological sequelae of low birthweight. British J. of Communication Dis., 3(2), 143-149.

19. Smith, R.M. and.McWilliams, B.J. (1968): Psycholinguistic abilities of children with clefts. Cleft Palate Journal, 15, 238-248.

20. Spriestersbach, D.C., Darley, F.L. and Morris, H.L. (1958): Language skills in children with cleft palate. J. Speech and Hearing Res., 1, 279-285.

21. Spriestersbach, D.C. and Sherman, D. (1968): Cleft Palate and Communication. Academic Press, New York and London.

22. Tisza, V.B. and Gumpertz, E. (1962): The parents' reaction to the birth and early care of children with cleft palate. Paediatrics, 30, 86-90. 